University of Wollongong

Research Online

Faculty of Engineering and Information

Faculty of Engineering and Information

Sciences - Papers: Part A

Sciences

January 2014

\title{
Austenite grain growth and the surface quality of continuously cast steel
}

Rian J. Dippenaar

University of Wollongong, rian@uow.edu.au

Christian Bernhard

University of Leoben

Siegfried Schider

Materials Centre Leoben

Gerhard Wieser

University of Leoben

Follow this and additional works at: https://ro.uow.edu.au/eispapers

Research Online is the open access institutional repository for the University of Wollongong. For further information contact the UOW Library: research-pubs@uow.edu.au 


\title{
Austenite grain growth and the surface quality of continuously cast steel
}

\author{
Abstract \\ Austenite grain growth does not only play an important role in determining the mechanical properties of \\ steel, but certain surface defects encountered in the continuous casting industry have also been \\ attributed to the formation of large austenite grains. Earlier research has seen innovative experimentation, \\ the development of metallographic techniques to determine austenite grain size and the building of \\ mathematical models to simulate the conditions pertaining to austenite grain growth during the \\ continuous casting of steel. Oscillation marks and depressions in the meniscus region of the \\ continuously casting mold lead to retarded cooling of the strand surface, which in turn results in the \\ formation of coarse austenite grains, but little is known about the mechanism and rate of formation of \\ these large austenite grains. Relevant earlier research will be briefly reviewed to put into context our \\ recent in situ observations of the delta-ferrite to austenite phase transition. We have confirmed earlier \\ evidence that very large delta-ferrite grains are formed very quickly in the single-phase region and that \\ these large delta-ferrite grains are transformed to large austenite grains at low cooling rates. At the higher \\ cooling rates relevant to the early stages of the solidification of steel in a continuously cast mold, delta- \\ ferrite transforms to austenite by an apparently massive type of transformation mechanism. Large \\ austenite grains then form very quickly from this massive type of microstructure and on further cooling, \\ austenite transforms to thin ferrite allotriomorphs on austenite grain boundaries, followed by \\ Widmanstätten plate growth, with almost no regard to the cooling rate. This observation is important \\ because it is now well established that the presence of a thin ferrite film on austenite grain boundaries is \\ the main cause of reduction in hot ductility. Moreover, this reduction in ductility is exacerbated by the \\ presence of large austenite grains.

\section{Keywords} \\ growth, quality, surface, grain, steel, austenite, continuously, cast \\ Publication Details \\ Dippenaar, R., Bernhard, C., Schider, S. \& Wieser, G. (2014). Austenite grain growth and the surface quality \\ of continuously cast steel. Metallurgical and Materials Transactions B: Process Metallurgy and Materials \\ Processing Science, 45 (2), 409-418.
}




\title{
Austenite Grain Growth and the Surface Quality of Continuously Cast Steel
}

\author{
RIAN DIPPENAAR, CHRISTIAN BERNHARD, SIEGFRIED SCHIDER, and \\ GERHARD WIESER
}

\begin{abstract}
Austenite grain growth does not only play an important role in determining the mechanical properties of steel, but certain surface defects encountered in the continuous casting industry have also been attributed to the formation of large austenite grains. Earlier research has seen innovative experimentation, the development of metallographic techniques to determine austenite grain size and the building of mathematical models to simulate the conditions pertaining to austenite grain growth during the continuous casting of steel. Oscillation marks and depressions in the meniscus region of the continuously casting mold lead to retarded cooling of the strand surface, which in turn results in the formation of coarse austenite grains, but little is known about the mechanism and rate of formation of these large austenite grains. Relevant earlier research will be briefly reviewed to put into context our recent in situ observations of the delta-ferrite to austenite phase transition. We have confirmed earlier evidence that very large delta-ferrite grains are formed very quickly in the single-phase region and that these large deltaferrite grains are transformed to large austenite grains at low cooling rates. At the higher cooling rates relevant to the early stages of the solidification of steel in a continuously cast mold, deltaferrite transforms to austenite by an apparently massive type of transformation mechanism. Large austenite grains then form very quickly from this massive type of microstructure and on further cooling, austenite transforms to thin ferrite allotriomorphs on austenite grain boundaries, followed by Widmanstätten plate growth, with almost no regard to the cooling rate. This observation is important because it is now well established that the presence of a thin ferrite film on austenite grain boundaries is the main cause of reduction in hot ductility. Moreover, this reduction in ductility is exacerbated by the presence of large austenite grains.
\end{abstract}

DOI: $10.1007 / \mathrm{s} 11663-013-9844-6$

(C) The Minerals, Metals \& Materials Society and ASM International 2013

\section{INTRODUCTION}

Austenite grain growth plays an important role in determining the mechanical properties of steel. With respect to the rolling of plain carbon steels in the hotstrip mill, for example, Militzer et al. ${ }^{[1]}$ argue that austenite grain growth is the dominant process in the reheating furnace as well as between rolling stands after completion of recrystallization. Because the austenite grain size has a dominant influence on the resulting ferrite grain size on subsequent cooling, it also plays a major role in determining the resulting mechanical properties of the steel following thermomechanical processing. In addition, the formation of transverse surface cracks that are experienced in the continuously cast strand have been attributed to the formation of large austenite grains that form in the near-surface area in the meniscus region of the mold. It is instructive to briefly review information on transverse surface cracks,

RIAN DIPPENAAR, Professor, is with the University of Wollongong, Wollongong, NSW, Australia. Contact e-mail rian@uow.edu.au CHRISTIAN BERNHARD, Professor, and GERHARD WIESER, Technical Officer, are with the University of Leoben, Leoben, Austria. SIEGFRIED SCHIDER, Technical Officer, is with the Materials Centre Leoben Forschung GmbH, Leoben, Austria.

Manuscript submitted January 23, 2013.

Article published online April 6, 2013. the formation of oscillation marks, hot-ductility measurements, and the determination of austenite grain size in a continuously cast steel slab to provide relevant background to the present investigation.

Transverse cracks are often experienced during the continuous casting of steel at the base of oscillation marks and/or surface depressions. These cracks are intergranular and propagate along boundaries of exceptionally large prior-austenite grains. ${ }^{[1-11]}$ Crowther and Mint $^{[5]}$ as well as Schmidt and Josefsson ${ }^{[6]}$ provided evidence that transverse cracks only occur in the presence of abnormally large austenite grains. Alvarez et $a l^{[7]}$ argued that cracks only occur in surface regions in the presence of abnormally large prior austenite grains when there is a ferrite film surrounding the grain boundaries. Tsai et al. ${ }^{[8]}$ provided convincing experimental evidence that transverse cracks follow the soft ferrite films that outline such large prior austenite grains. Since these cracks propagate along prior austenite grain boundaries and they cut through preexisting dendrite arms, they argued that these large austenite grains are not related to dendrite growth and that they develop after the surface has completely solidified. Szekeres ${ }^{[2]}$ coined the term "blown-grains" to describe these abnormally large prior austenite grains, typically larger than $1 \mathrm{~mm}$ in diameter. Moreover, he contends that the existence of abnormally large prior austenite 
grains is the key factor and mandatory prerequisite for the propagation of transverse surface cracks. ${ }^{[2]}$ Moon studied the influence of large prior-austenite grains on hot ductility ${ }^{[9]}$ and Dippenaar et al. ${ }^{[10]}$ maintained that little study has been done in this area, and little information is available on the origins of these very large austenite grains.

Because transverse surface cracks seem to initiate at the roots of oscillation marks, it is pertinent to briefly refer to the origins of oscillation marks. A unique consequence of mold oscillation, which has become standard practice in the continuous casting of steel, is the presence of circumferential grooves oriented transverse to the casting direction. These grooves can be very distinct, they are approximately regularly spaced and because at least one groove corresponds to each cycle of mold oscillation, the term "oscillation marks" was coined. ${ }^{[12]}$ These periodic depressions (oscillation marks) are routinely observed on the surface of steel slabs manufactured by continuous casting processes, and they significantly alters the local heat transfer, fluid flow, and solidification in the meniscus region. ${ }^{[13]}$ Oscillation marks can be quite deep and microscopic examination points to a very complex interaction between mold meniscus and mold flux. ${ }^{[14]}$ When deep oscillation marks form, the local heat transfer conditions are altered significantly, and cracks can originate at the roots of these oscillation marks. Figure 1 shows an example of the formation of cracks at the roots of oscillation marks. It is interesting to note that all the cracks are associated with oscillation marks, but not all oscillation marks contain cracks. It is furthermore interesting to note that very large austenite grains are formed at these deep oscillation marks and that cracks propagated along the ferrite films that are positioned along the grain boundaries of these very large austenite grains.

Chimani and Mörwald ${ }^{[15]}$ have used a micromechanical modeling technique to show that in a structure where austenite grains are surrounded by a thin ferrite

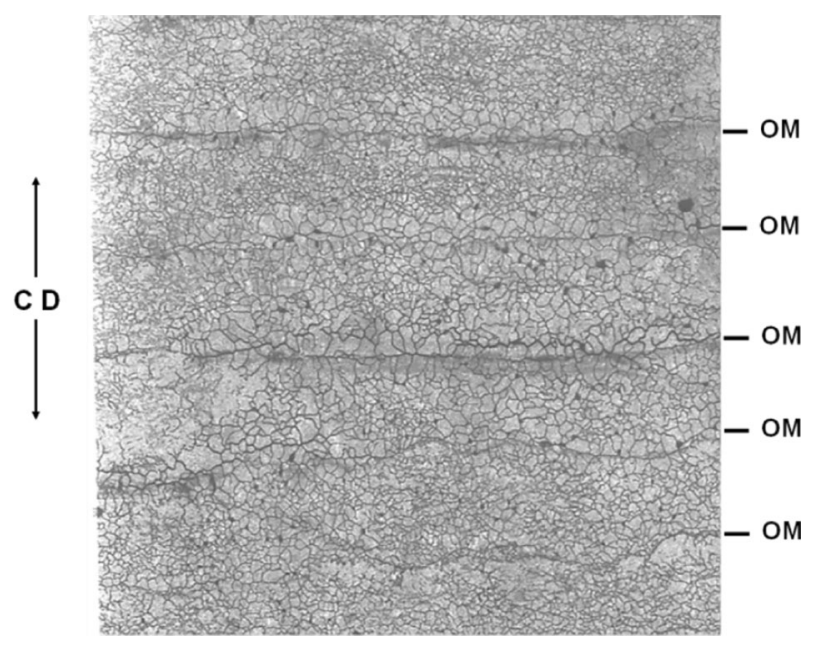

Fig. 1-Large prior austenite grains formed in the vicinity of oscillation marks on the broad face of a continuously cast slab of peritectic composition. Also shown are transverse surface cracks that formed at the roots of oscillation marks. $\mathrm{CD}=$ Casting Direction; $\mathrm{OM}=$ Oscillation Marks. ${ }^{[2]}$ film and after the initiation of plastic flow, the strain concentrates within the thin, softer, ferrite layer to a value several times the global strain. By their quantitative analysis, they have also clearly shown that the strain concentration decreases significantly with an increase of the percentage ferrite and they have therefore provided quantitative proof of a qualitative perception that had prevailed for some time with respect to the experimentally observed so-called ductility trough. Using a similar modeling technique and comparing the modeling calculations with fractography, Chimani et al. ${ }^{[16]}$ have shown that fracture occurs by a pseudo-brittle fracture mode, despite the observed microductile nature of the damage. It follows from this analysis that the larger the austenite grain size, the greater will be the propensity for the formation of brittle cracks along austenite grain boundaries.

In an attempt to establish a correlation between austenite grain size and the susceptibility to crack formation during unbending of a continuously cast strand, Moon ${ }^{[9]}$ determined the hot ductility in Fe-C alloys as a function of austenite grain size.

Having established that transverse surface cracks form at the roots of oscillation marks and that they are associated with large austenite grains, it is necessary to explore the possible reasons for the formation of these very large austenite grains. In an interesting study, Maehara et $a l^{[17]}$ held a 0.06 pct $\mathrm{C}$ steel specimen isothermally at $1723 \mathrm{~K}\left(1450{ }^{\circ} \mathrm{C}\right)$ and found that this specimen developed excessively large austenite grains. They were not able to determine the delta-ferrite grain size by the experimental techniques they used and the question arose as to whether reheating to $1723 \mathrm{~K}$ $\left(1450{ }^{\circ} \mathrm{C}\right)$ (within the delta-ferrite phase field) resulted in large delta-ferrite grains that subsequently developed in large austenite grains on the transformation of delta to gamma on cooling. The other mechanism, by which large austenite grains can form, is evidently by rapid grain growth of the austenite grains themselves, once formed. The same authors also found that the largest austenite grains developed in steel of near-peritectic composition. This finding raises the further question as to whether the rate and mechanism of the peritectic transformations after the peritectic reaction make impacts on the subsequent development of large austenite grains or whether the large austenite grains observed are merely the result of rapid austenite grain growth at temperatures in the vicinity of the peritectic temperature.

Microstructural development is intimately linked to mechanical properties, and the finding that transverse cracks are usually worse on the strand face that undergoes tensile strain during straightening (unbending) has prompted hot-ductility tensile tests of steels in the temperature range of unbending of the strand and at strain rates similar to those in a caster. ${ }^{[10]}$ Most steels exhibit a ductility trough with a minimum in ductility close to the $\mathrm{Ae}_{3}$-temperature where weaker ferrite starts to form on austenite grain boundaries. This is often referred to as the first ductility trough. ${ }^{[18]}$ There seems to be a greater propensity for cracking in microalloyed steels, and the alloying elements $\mathrm{Al}, \mathrm{N}, \mathrm{S}, \mathrm{Nb}$, and $\mathrm{V}$ can 
lower the minimum ductility and/or extend the weakness to higher temperatures, suggesting that precipitates that form on the austenite grain boundaries before ferrite formation, can exacerbate the ductility loss, ${ }^{[2,11,17-19]}$ the so-called second ductility trough. ${ }^{[18]}$ In an attempt to isolate the effect of austenite grain size from precipitation effects on hot ductility, Moon ${ }^{[9,10]}$ used binary Fe-C alloys of various carbon contents to determine austenite grain growth as a function of temperature in re-heated specimens. He furthermore partially melted cylindrical specimens in a Gleeble3500 thermomechanical simulator, cooled them at different rates to simulate various continuous casting techniques, and assessed the austenite grain growth. His findings with respect to austenite grain growth as a function of temperature in re-heated specimens are in excellent agreement with the empirical austenite grain growth rate equation proposed by Miettinen et al. ${ }^{[20,21]}$ In brief, the austenite grain size varies essentially as a linear function of temperature. Hence, Fe-C alloys of peritectic composition will have the largest austenite grains because at this composition, the austenite phase reaches the highest temperature before it transforms to delta ferrite. These findings are important for assessing austenite grain growth in the re-heat furnace.

With respect to microstructural development in the continuously cast strand, it is of great importance to understand the formation and growth of austenite grains at the surface as well as below the surface. Bernhard et al. ${ }^{[18,21]}$ have developed metallographic techniques to determine the austenite grain size of continuously cast steel slabs and in addition, developed an experimental technique to simulate the conditions pertaining in a continuous casting strand. They found excellent correlation between austenite grain growth in commercially cast strands and in their experimental simulations, the so-called Submerged Split Chill Tensile test (SSCT test). They have furthermore developed a model to predict the growth of austenite grains and were able to quantitatively predict austenite grain growth. In addition, they have simulated the reduced heat-transfer rate at the roots of oscillation marks and have shown that this reduced heattransfer rate leads to the formation of large austenite grains at the roots of oscillation marks. ${ }^{[18]}$

In the course of the continuous casting of steel and following initial solidification, the delta-ferrite to austenite phase transition or the peritectic phase transformation occurs when the newly formed solid shell is relatively thin, but conclusions about the mechanism and rate of these transitions have mostly been drawn from indirect experiments and very little study has been done on the direct observation of events. A serious impediment has been the difficulty of studying these transformations in situ because of the complexities associated with conducting high-resolution metallography at these high temperatures. The use of hightemperature laser-scanning confocal microscopy have overcome at least some of these barriers and in an attempt to study the fundamentals of the delta-ferrite to austenite phase transition, Niknafs ${ }^{[22,23]}$ heated an $\mathrm{Fe}-0.05$ pct $\mathrm{C}$ steel into the delta-ferrite phase field and studied the transformation of delta-ferrite to austenite. On heating, austenite transforms to deltaferrite and at a temperature of $1723 \mathrm{~K}\left(1450{ }^{\circ} \mathrm{C}\right)$ the delta-ferrite grains are large, typically more than a millimeter in diameter and on slow cooling, the large delta-ferrite grains are transformed into excessively large austenite grains. The transformation of delta-ferrite to austenite on cooling commences at delta-ferrite triple points. Austenite then grows preferentially and by a mechanism of diffusional growth as planar growth fronts along the delta-ferrite grain boundaries and forms large austenite grains. These findings are in agreement with those of earlier researchers. At cooling rates higher than about $70 \mathrm{~K}\left(70^{\circ} \mathrm{C}\right) / \mathrm{min}$, delta-ferrite transformed by a massive type of phase transformation, but Niknafs was not able to determine how this massive type of structure transforms to austenite. Preliminary neutron diffraction studies indicated that large deltaferrite grains transform to large austenite grains, but these initial results were not conclusive because the delta-ferrite grains grow so large that only a few crystallites are oriented in such a way that Laue's condition is fulfilled, leading to an inhomogeneous intensity distribution on the Debye-Scherer rings and hence, a spotty character. Pursuing the earlier findings of Niknafs, we used a newly designed high-temperature laser-scanning confocal microscope to study in more detail, the transformation of delta-ferrite to austenite on cooling a $\mathrm{Fe}-0.05$ pct $\mathrm{C}$ binary alloy from the deltaferrite phase.

The main objective of the current investigation was to determine how austenite grains develop from the massive type of microstructure that evolves on fast cooling from the delta-ferrite phase. Since the cooling rate required to form this massive type of austenite structure is lower than the expected cooling rate in the meniscus region of a continuous casting mold, it is likely that delta-ferrite can transform to austenite by this massive type of morphology when the solidified shell of the strand is very thin. Hence, it is expected that the local detachment of the shell due to shrinkage, is exacerbated by the very fast delta-ferrite to austenite phase transformation. In addition, the sudden transformation will increase the strain rate of the thin shell, which results from the imposed stress, which in turn is a consequence of shrinkage. If in addition, large austenite grains form in the meniscus region of the shell, the risk of surface crack formation is significantly increased since it has been proven beyond reasonable doubt that the presence of large austenite grains in the surface region of the strand is a prerequisite to the formation of surface cracks during unbending of the strand. Hence, we attempted to establish how austenite behaves subsequent to the occurrence of the massive type of phase transformation on the transition from delta-ferrite to austenite. This was done on two fronts: we observed in situ the massive type of phase transition in a hightemperature microscope and the subsequent development of austenite grains. We then correlated these findings with the calculated temperature distribution and cooling rate in the vicinity of oscillation marks in the meniscus region of a simulated continuous casting strand. 


\section{EXPERIMENTAL DETAILS}

A Fe- 0.05 pet $\mathrm{C}$ alloy was prepared in a laboratory scale vacuum induction-melting furnace and deoxidized by aluminum (0.016 pet $\mathrm{Al} ; 0.002$ pet $\mathrm{P} ; 0.002$ pet $\mathrm{S}$; 0.0015 pct $\mathrm{N}$; compositions in pet by mass). Solidified ingots were reheated to $1473 \mathrm{~K}\left(1200{ }^{\circ} \mathrm{C}\right)$ and then hot rolled into $15-\mathrm{mm}$-thick plates using a laboratory scale rolling mill. For the purposes of high-temperature microscopical investigations, $7.0-\mathrm{mm}$ diameter cylindrical specimens were machined from these plates with their axes parallel to the rolling direction; $1.0-\mathrm{mm}$ or 4-mm-thick slices were then cut from these cylinders perpendicular to the longitudinal axis. These thin disks were polished metallographically, thoroughly cleaned, and inserted into the infrared furnace within the hightemperature laser-scanning confocal microscope. A Lasertech model VL2000DX-SVF17SP laser-scanning confocal microscope in combination with an infrared heating furnace was used. The violet laser has a wavelength of $405 \mathrm{~nm}$; the maximum resolution is $0.14 \mu \mathrm{m}$ with a pixel resolution of $0.03 \mu \mathrm{m}$. Following several cycles of vacuum sucking and flushing with ultra-high purity argon, specimens were examined under a positive flow of argon. The use of a high integrity gaspurification train insured that no oxidation occurred in the course of the metallographic observations. Specimens were generally heated into the delta-ferrite phase field and then cooled at different rates to study the deltaferrite to austenite phase transition.

In the course of an earlier investigation, a model was developed to predict the austenite grain size at the surface of a continuously cast steel slab. ${ }^{[21]}$ Moreover, using realistic boundary conditions the temperature distribution in the vicinity of oscillation marks was calculated by the use of a heat transfer model. In this instance, the temperature distribution around oscillation marks was calculated at the time the strand leaves the mold and enters the water-cooled region. ${ }^{[18]}$ In the present investigation, these same models were used to calculate the temperature distribution in the vicinity of oscillation marks in the meniscus region of the continuous casting mold with a view to assess austenite grain growth in this region of the mold, especially in the presence of oscillation marks.

\section{RESULTS}

On heating the $\mathrm{Fe}-0.05$ pct $\mathrm{C}$ alloy into the deltaferrite phase field, typically to $1723 \mathrm{~K}\left(1450{ }^{\circ} \mathrm{C}\right)$, very large delta-ferrite grains formed very quickly. On cooling at rates lower than about $100 \mathrm{~K}\left(100{ }^{\circ} \mathrm{C}\right) / \mathrm{min}$, the delta-ferrite transformed to austenite ostensibly by a mechanism of diffusional growth. Nucleation generally occurred at triple points and growth progressed along grain boundaries and also into the delta-ferrite grains as shown in Figure 2(a).

Growth occurred essentially by a near-planar growth front and the growth along grain boundaries was faster than into the grains. It was not the purpose of the current study to measure the growth rates, but the findings of Liu et al. ${ }^{[24]}$ are in agreement with our observations. Niknafs ${ }^{[23]}$ determined quantitatively that the initial growth rate of austenite along delta-ferrite grain boundaries in the same $\mathrm{Fe}-0.05$ pct $\mathrm{C}$ alloy is much higher than that of austenite growing into delta-ferrite, but that this difference diminishes with time as growth progresses. Following partial transformation of deltaferrite to austenite shown in Figure 2(a), the temperature was cycled several times by $\pm 20 \mathrm{~K}\left(20^{\circ} \mathrm{C}\right)$ and we have found that the transformation of delta-ferrite into austenite and the reverse transformation of austenite to delta-ferrite are completely reversible.

Further cooling led to the formation of alpha-ferrite on austenite grain boundaries as shown in Figure 2(b). However, it is evident that new austenite grain boundaries had formed before the transformation to alpha ferrite occurred.

At cooling rates higher than about $100 \mathrm{~K}\left(100{ }^{\circ} \mathrm{C}\right) /$ min, the mode of transformation changed completely to a type of massive transformation. A typical example of the resulting microstructure is shown in Figure 3. Figure 3(a) shows the delta-ferrite structure immediately before it transformed to austenite and Figure 3(b) the massive type of transformation product. In this instance the transformation occurred over a temperature range of $80 \mathrm{~K}\left(80^{\circ} \mathrm{C}\right)$.

It is pertinent to note that the temperature indicated on the video frame is not the actual temperature of the specimen, but that of the control thermocouple. It is also important to note that the background structure observed in Figure 3(a) is the result of the characteristics of the high-temperature laser-scanning confocal microscope. When a specimen is heated from room temperature to $1723 \mathrm{~K}\left(1450{ }^{\circ} \mathrm{C}\right)$, ferrite transforms to austenite at about $1173 \mathrm{~K}\left(900{ }^{\circ} \mathrm{C}\right)$. When this reaction occurs, the newly formed austenite grains are made visible because the volume change as a result of the phase transformation delineates the new grain boundaries. These grooves remain there and when the austenite to delta-ferrite transformation occurs, new delta-ferrite grain boundaries are formed, but the grooves formed by the ferrite to austenite phase transition remain there and will only smooth out by surface diffusion at these high temperatures if sufficient time is allowed. Hence, what we observe are the remnants of the austenite grains that formed on the ferrite to austenite phase transition.

Although it was not the purpose of the current study to determine the critical cooling rate at which the planar-growth morphology changes to a massive type of transformation morphology, our findings are in large measure in agreement with those of earlier researchers. For example, Shibata et al. ${ }^{[25]}$ found that following the peritectic reaction, delta-ferrite transformed to austenite at such a high rate that the rate of the transformation cannot be controlled by diffusion. Liu et al. ${ }^{[24]}$ found that at a cooling rate of $600 \mathrm{~K}\left(600^{\circ} \mathrm{C}\right) / \mathrm{min}$, deltaferrite transformed into austenite in a "sword-like" fashion. Kikuchi et al. ${ }^{[26]}$ detected "sword-like" transformation products at cooling delta-ferrite at $300 \mathrm{~K} / \mathrm{min}$ and argued that this structure forms by a diffusionless mechanism. Niknafs ${ }^{[23]}$ observed these "sword-like" 


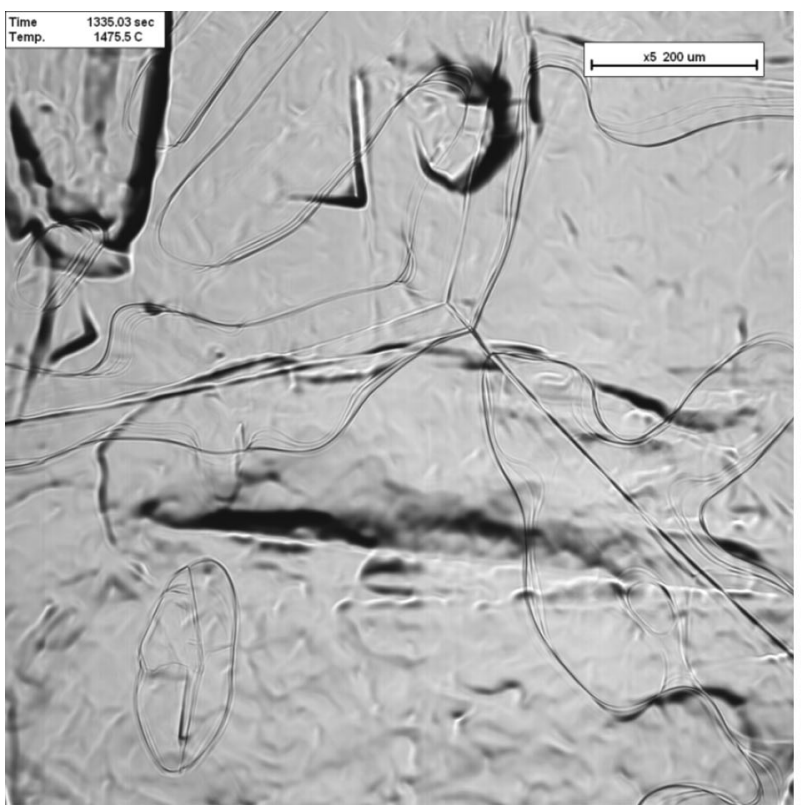

(a)

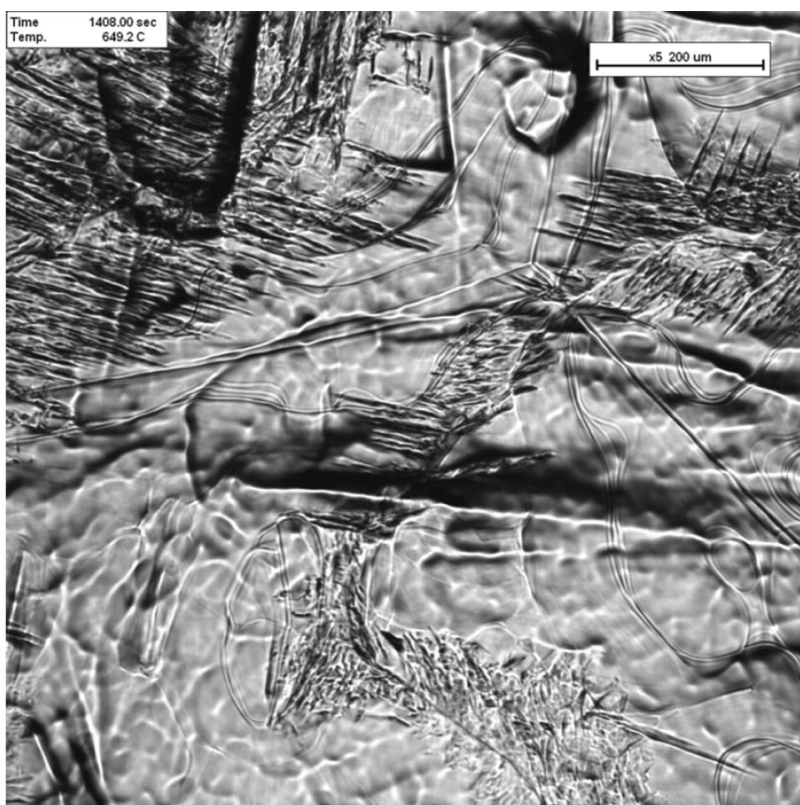

(b)

Fig. 2 - Growth of austenite at delta-ferrite triple points and along grain boundaries, cooling rate $20 \mathrm{~K}\left(20{ }^{\circ} \mathrm{C}\right) /$ min $(a)$ and the growth of alpha-ferrite on austenite grain boundaries $(b)$.

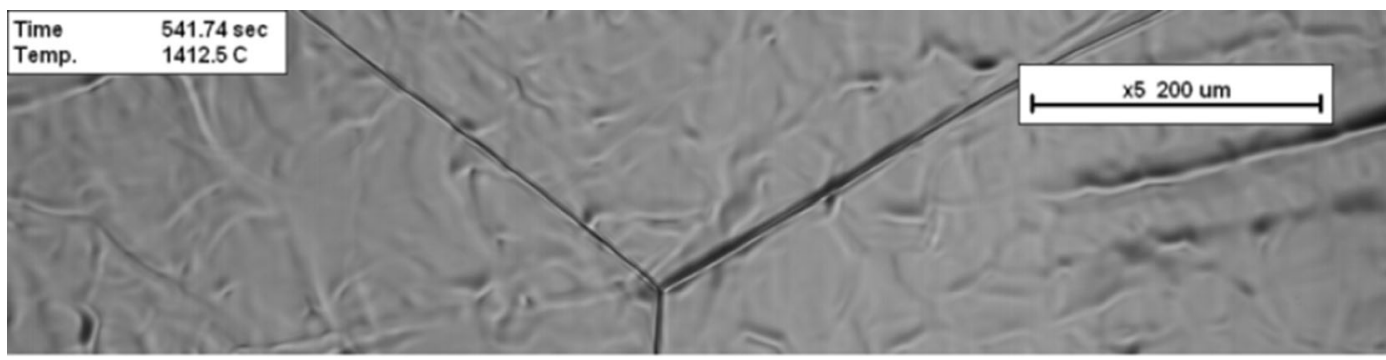

(a)

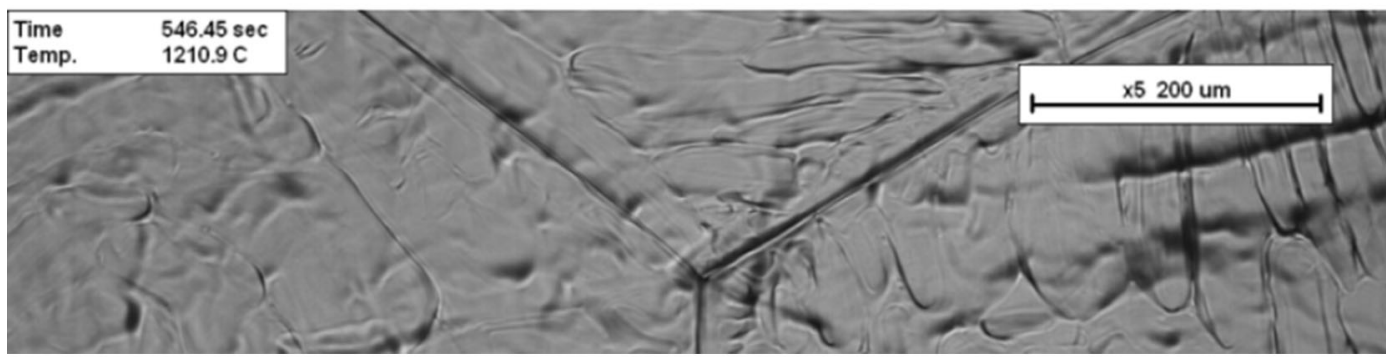

(b)

Fig. 3-Example of massive type of transformation occurring at a triple point in delta-ferrite, cooling rate $3000 \mathrm{~K}\left(3000{ }^{\circ} \mathrm{C}\right) / \mathrm{min} .(a)$ is the delta-ferrite structure immediately before the transformation and $(b)$, the microstructure resulting from the transformation. Recording speed 60 frames per second. In (b) the grooves of the preexisting delta-ferrite grain boundaries are still visible.

structures upon cooling a $\mathrm{Fe}-0.05$ pet $\mathrm{C}$ alloy at rates higher than $70 \mathrm{~K} / \mathrm{min}$ The massive type of reaction we observed did not display the "sword-like" morphology that Liu et al. ${ }^{[24]}$ and Kikuchi et al. ${ }^{[26]}$ observed, but it was very similar to the observations Niknafs made. ${ }^{[23]}$ The morphology resembles "dendrite" tips that grow from below the surface of the specimen as shown in Figure 3. Figure 4(a) shows another example of the delta-ferrite structure before the occurrence of a massive type of transformation; and Figure 4(b), shows the massive type of transformation product. At a cooling rate of $2100 \mathrm{~K}\left(2100{ }^{\circ} \mathrm{C}\right) / \mathrm{min}$, the transformation was completed within $137 \mathrm{~K}\left(1137^{\circ} \mathrm{C}\right)$.

Of greater interest in the present context is the determination of the relationship between the massive type of structural morphology and the growth of austenite grains. A 4-mm-thick specimen [instead of the usual $1.0 \mathrm{~mm}$ ] was heated up into the delta-ferrite 
phase field $\left[1793 \mathrm{~K}\left(1520^{\circ} \mathrm{C}\right)\right.$ shown on the video frame is equivalent to a real specimen temperature of $1743 \mathrm{~K}$ $\left.\left(1470{ }^{\circ} \mathrm{C}\right)\right]$, equilibrated for 2 minutes and then cooled at a rate of $600 \mathrm{~K}\left(600{ }^{\circ} \mathrm{C}\right) / \mathrm{min}$ to a temperature within the austenite phase-field $\left[1623 \mathrm{~K}\left(1400{ }^{\circ} \mathrm{C}\right)\right.$ on the video frame is equivalent to $1623 \mathrm{~K}\left(1350{ }^{\circ} \mathrm{C}\right)$ ]. Figure 5(a) shows the delta-ferrite grains immediately before the transformation and the triple-point in the delta-ferrite structure is clearly delineated. Figure 5(b) shows the transformation product. The transformation occurred over a temperature range of $44 \mathrm{~K}\left(44^{\circ} \mathrm{C}\right)$. Because of the imposed temperature distribution in the infrared furnace, the bottom of the specimen is at a slightly lower temperature that the observed top-surface and hence, lath or dendritic type growth occurs from below the observed surface. Depending on grain orientation relative to the direction of growth of the laths/dendrites propagating by a massive-like means, different morphologies are observed as shown in the video frames.

Following the transformation of delta-ferrite to austenite, the specimen was cooled to room temperature at an initial cooling rate of $2100 \mathrm{~K}\left(2100{ }^{\circ} \mathrm{C}\right) / \mathrm{min}$. Figure 6(a) shows the initial formation of ferrite on the austenite grain boundaries that had evolved from the massive type of transformation product shown in Figure 5(b). It is evident that the austenite grains that grew subsequent to the formation of the massive structure bear no relation to the preexisting massive type of austenite morphology. Figure 6(b) shows the further growth of Widmanstätten ferrite plates into austenite grains. It is clear that these plates cross the preexisting structure at random and there is no relationship between the growth of the ferrite plates and the preexisting structure. Hence, austenite grains have grown from the massive type of austenite structure. Moreover, these newly grown austenite grains are very large.

In order to fully interpret the meaning of these observations, it is necessary to briefly refer to the characteristics of observations in the high-temperature laser-scanning confocal microscope. Due to surface tension and differences in orientation of grains, grooves form during heating and because the incident laser beam is scattered at these grooves, grain boundaries are made visible. When a phase transformation occurs, these grooves remain visible although they are not grain boundaries any longer. Hence, when the delta-ferrite to austenite phase transformation occurs, the preexisting delta-ferrite grain boundary structure is still visible and the relationship between the preexisting delta-ferrite grains (now only grooves) and the newly formed austenite can be observed. For example, the positions of the delta-ferrite grain boundaries can be clearly seen in Figures 3(a), but when the phase transformation occurred, these grain boundaries disappeared, but their former positions are still clearly delineated in Figure 3(b) because the grooves of the preexisting grains can still exist and can be observed.

The fact that the specimen can be observed throughout the cooling cycle and the images recorded on video further enables a comparison between the evolving microstructures as a function of time and the final microstructure. For example, Figure 7 shows a composite ("stitched") micrograph of the final microstructure of the specimen shown in Figures 5 and 6 . The positions of the delta-ferrite grains and those of the austenite grains are enhanced for the purposes of illustration. Comparison with the evolving microstructures recorded on video frames, confirm this structure. It is evident that very large delta-ferrite grains translate to very large austenite grains although the initial deltaferrite to austenite transformation occurred by a massive type of morphology.

The formation of large austenite grains from large delta-ferrite grains were observed irrespective of the phase transformation occurring by a diffusionally controlled transformation mechanism (planar growth fronts) or by a massive type of transformation mechanism. Very large delta-ferrite grains formed within seconds of heating an austenite structure into the delta-ferrite phase field and the size of the delta-ferrite grains did not seem to depend on the austenite grain size. The kinetics of delta-ferrite grain growth could not be studied in detail because time is required for deltaferrite grain-grooves to be made visible, but large deltaferrite grains, millimeters in diameter, were visible within a matter of seconds. In similar vein, it was not possible to study the kinetics of the evolvement of equiaxed austenite grains from the massive type of transformation product because time is required to make visible the newly formed grain boundaries. However, there is no doubt that large austenite grains form from large delta-ferrite grains on slow cooling. At high cooling rates, a massive type of austenite forms from delta-ferrite, and large austenite grains evolve from this massive type of transformation product.

Having established that large austenite grains form from large delta-ferrite grains at high temperature, it is necessary to establish the likelihood of these observations being relevant to the continuous casting of steel. For these purposes, the temperature distribution within the strand in the vicinity of the meniscus of a continuous caster was calculated in the absence and in the presence of oscillation marks. The same procedure, input data and boundary conditions described by Bernhard et al. ${ }^{[18,27]}$ were used, except that the heat flux in the vicinity of the meniscus instead of at the exit of the mold was used as a boundary condition. The resulting calculated temperature distribution is shown in Figure 8.

The oscillation mark was assumed to be filled with air and the casting speed was $1.2 \mathrm{~m} / \mathrm{min}$. It follows from the calculations that the initial cooling rate on the surface away from the oscillation mark is more than $4000 \mathrm{~K}$ $\left(4000{ }^{\circ} \mathrm{C}\right) / \mathrm{min}$ while at the root of an oscillation mark the cooling rate is reduced to about $600 \mathrm{~K}\left(600{ }^{\circ} \mathrm{C}\right) / \mathrm{min}$. It follows furthermore that the root of the oscillation mark will be within the delta-ferrite phase field for between 7 and 10 seconds. This means that there is a temperature difference of $150 \mathrm{~K}\left(150{ }^{\circ} \mathrm{C}\right)$ between the bulk surface temperature of the strand and the root of a 0.2 -mm-deep oscillation mark after 6 seconds $(400 \mathrm{~mm}$ below the meniscus). It also means that the cooling rate at the root of an oscillation mark is still high enough to 


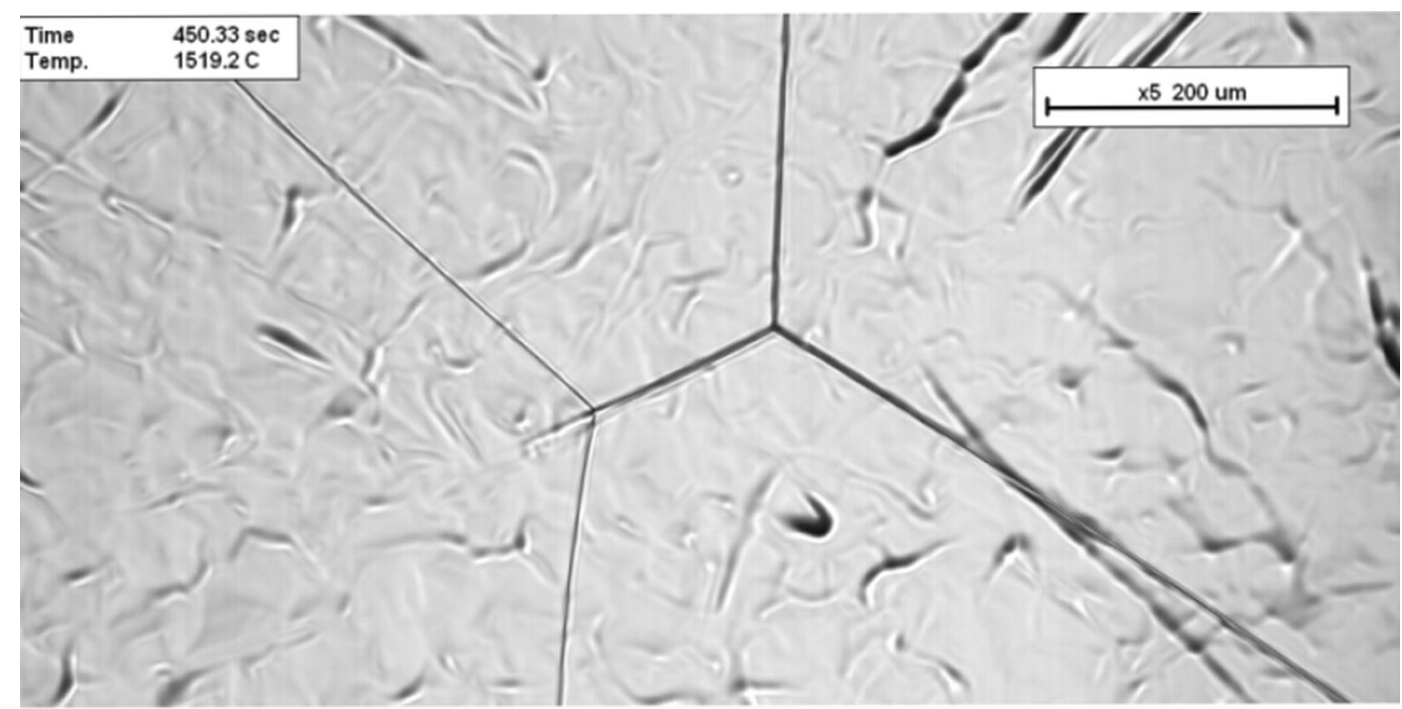

(a)

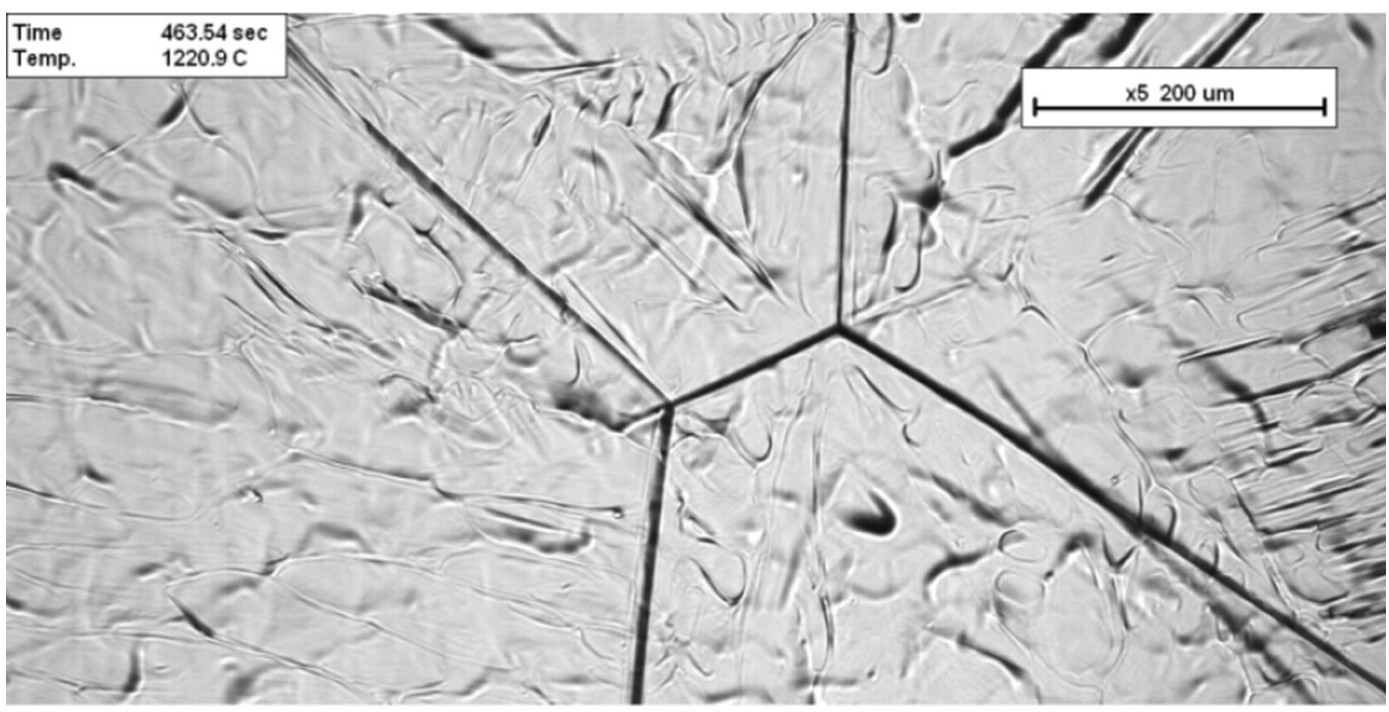

(b)

Fig. 4-Example of a massive type of phase transformation from delta-ferrite to austenite. Cooling rate $2100 \mathrm{~K}\left(2100{ }^{\circ} \mathrm{C}\right) / \mathrm{min}$. $(a)$ is the delta-ferrite structure immediately before the transformation; and $(b)$ the microstructure resulting from the transformation. The grooves of the preexisting delta-ferrite grain boundaries are still visible. Recording speed 30 frames per second.

cause the delta-ferrite to austenite phase transition to occur by a massive type of mechanism.

\section{DISCUSSION}

The current investigation was prompted by two scientifically interesting and industrially important questions. First, several earlier researchers have shown that delta-ferrite transforms to austenite by a massive type of phase transformation in low-carbon steel at high cooling rates, but the subsequent behavior of this microstructural morphology has not yet been clarified. From an industrial point of view it is important to understand how ferrite is formed on transformation of this massive type of morphology. Second, several researchers have argued that abnormally large austenite grains form at the roots of oscillation marks during the continuous casting of steel and convincing experimental evidence has been produced in support of this argument. However, why and how these abnormally large austenite grains actually form is still a matter of controversy. In order to design remedial action in practice, it is important to better understand the causes of abnormal grain growth in the meniscus region of the continuous casting strand because it is these abnormally large austenite grains that lead to surface cracks during unbending of the strand.

We have studied the solid-state delta-ferrite to austenite phase transition in a binary $\mathrm{Fe}-0.05$ pct $\mathrm{C}$ alloy to avoid the complications of solidification and furthermore to eliminate the effect of other alloying elements, specifically grain refiners. The Lasertech VL2000DXseries laser-scanning confocal microscope has a much 


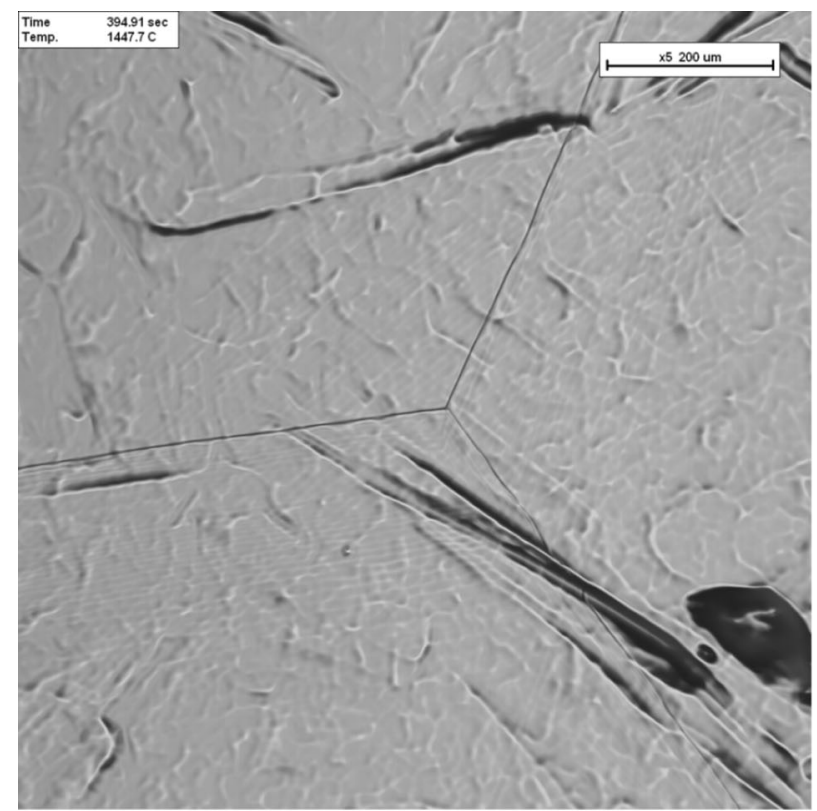

(a)

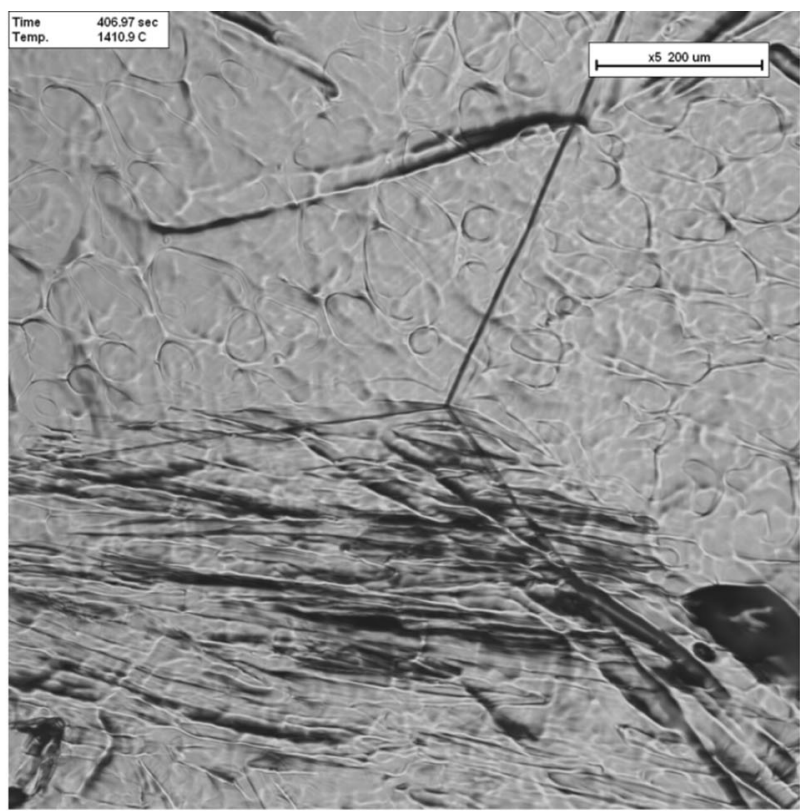

(b)

Fig. 5-Delta-ferrite to austenite phase transformation in a 4-mm-thick specimen at a cooling rate of $600 \mathrm{~K}\left(600{ }^{\circ} \mathrm{C}\right) / \mathrm{min}$. $(a)$ shows the delta-ferrite structure immediately before transformation and $(b)$ two variants of the massive type of transformation product. The grooves of the preexisting delta-ferrite grain boundaries are still visible.

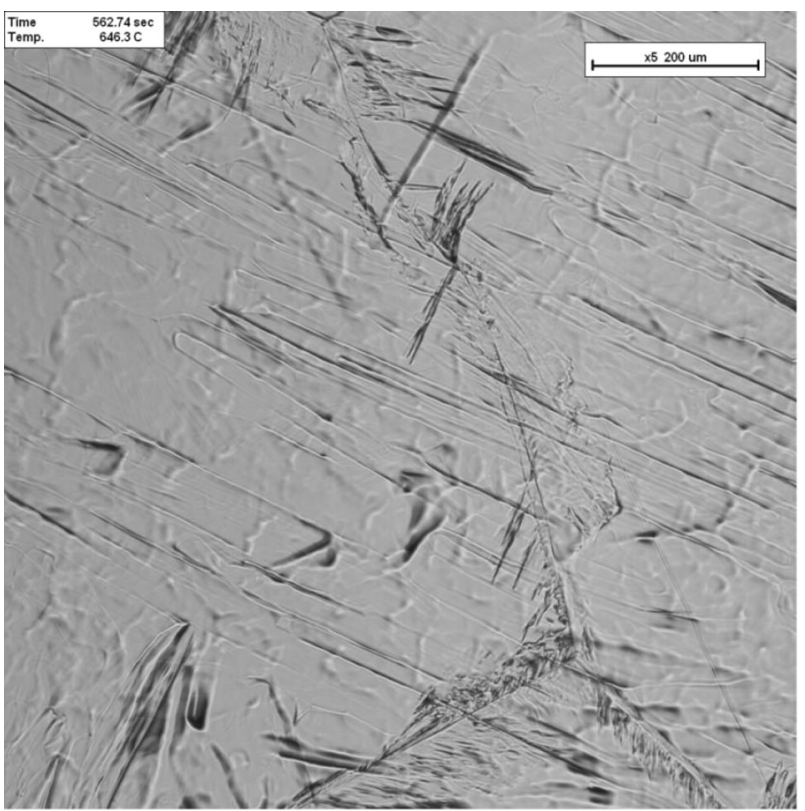

(a)

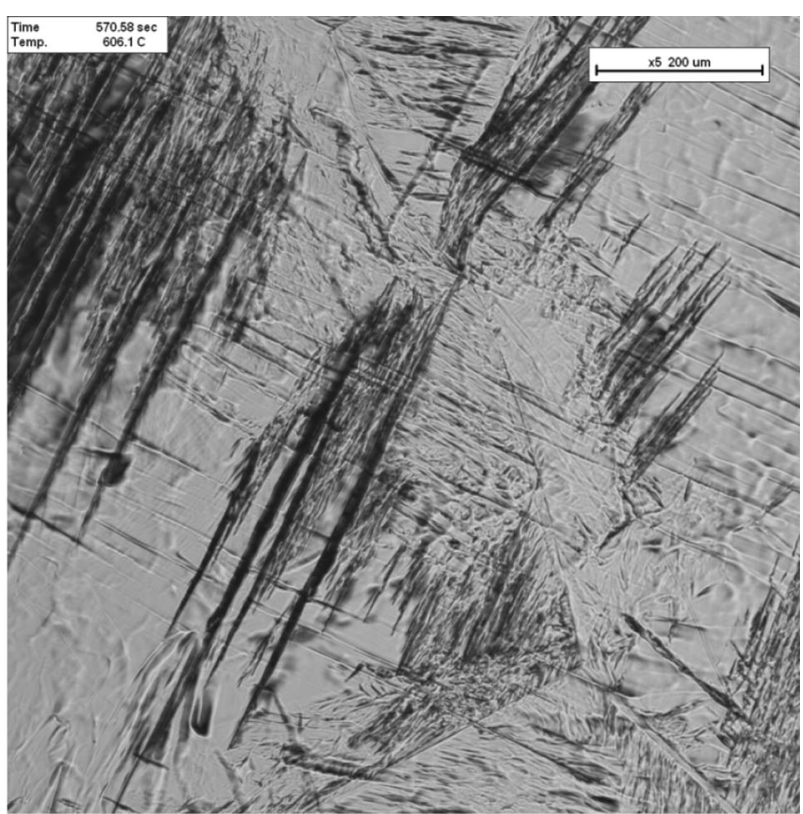

(b)

Fig. 6-Transformation of gamma to alpha in the same 4-mm-thick specimen shown in Fig. 5. (a) shows the very initial stages of alpha-ferrite formation on austenite grain boundaries. (b) shows the further growth of Widmanstätten ferrite plates into austenite, crossing the preexisting massive austenite structure.

higher resolution that the microscopes used in earlier studies and in addition, it is capable of recording at a higher frame-rate. Hence, we repeated some of the earlier experiments to take advantage of the improved capabilities.

Very large grains formed immediately upon heating into the delta-ferrite phase field as shown in Figure 7.
The massive type of transformation product of the delta-ferrite to austenite transition was observed at cooling rates higher than about $100 \mathrm{~K}\left(100{ }^{\circ} \mathrm{C}\right) / \mathrm{min}$ in agreement of earlier findings. However, micrographs of much higher resolution were obtained, and it was clear that the so-called sword-like structure actually developed by the growth of laths and dendritic-type 


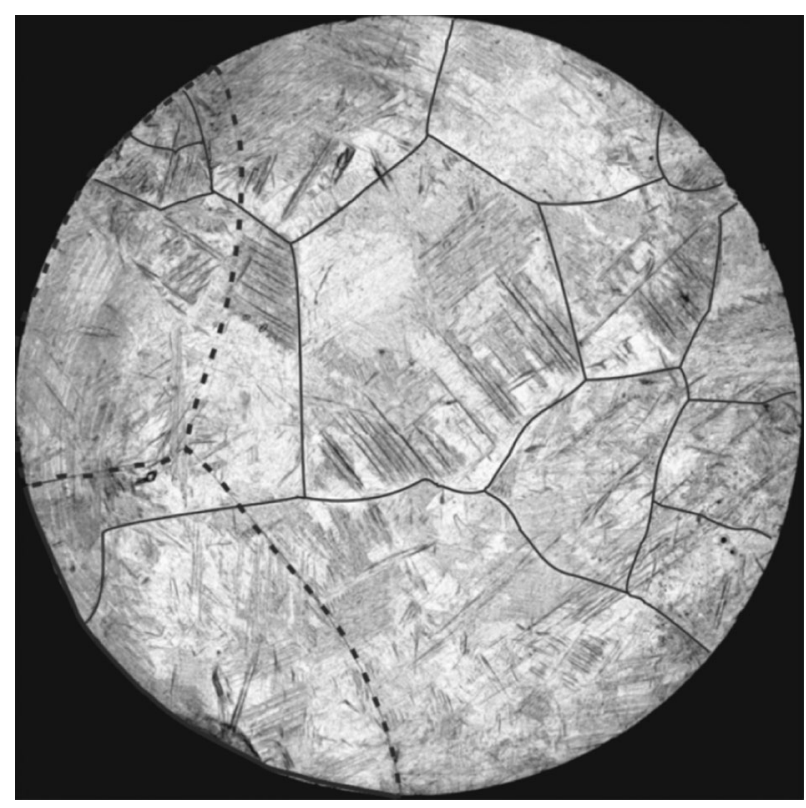

Fig. 7-The positions of preexisting delta-ferrite grains (dashed lines) and preexisting austenite grains (continuous lines) that had transformed to alpha-ferrite by Widmanstätten ferrite plate growth morphology are shown in this composite ("stitched") micrograph. Scale: The diameter of the specimen shown is $7.0 \mathrm{~mm}$.

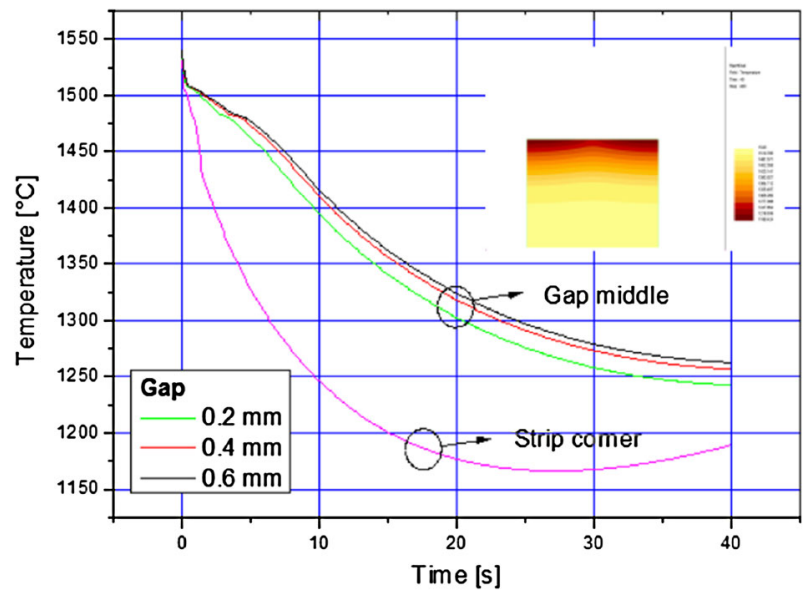

Fig. 8 - Calculated temperature distribution in the meniscus region of a continuously cast slab vs time. Casting speed $1.2 \mathrm{~m} / \mathrm{min}$.

morphologies as shown in Figures 3(b), 4(b) and 5(b). Because a video recording rate of 60 frames/sec (as opposed to 30 frames/sec in the earlier models) could be utilized, it was possible to determine the starting and the ending temperatures of the transformation much more accurately.

Subsequent to the phase transition, an equiaxed austenitic structure emerged, and very large austenite grains formed as shown in Figure 7. On being cooled further, ferrite formed on the austenite grain boundaries, and the growth of the ferrite into the austenite occurred mostly by Widmanstätten ferrite-plate growth. It was not possible to study the rate of nucleation and growth of the austenite grains from the massive type of structure because it takes considerable time for the austenite grain boundaries to become visible. However, large austenite grains were formed irrespective of the cooling rate, after the delta-ferrite to austenite phase transformation. Hence, from an industrial point of view, the occurrence of a massive type of phase transformation is of greatest significance in the meniscus region of the continuous casting mold. The volume change associated with the delta-ferrite to austenite phase transformation imposes significant stress on the thin solidifying shell and if this transformation occurs suddenly, as in the case with the massive type of transformation, the strain rate is increased and shell bending is exacerbated. The sudden contraction of the thin shell is also likely to increase the occurrence of hotspots and hence, shell thinning.

Moon et al..$^{10]}$ have shown to what extent hot ductility [ductility in the temperature region $1000 \mathrm{~K}$ to $1400 \mathrm{~K}\left(1273{ }^{\circ} \mathrm{C}\right.$ to $\left.\left.1673{ }^{\circ} \mathrm{C}\right)\right]$ is affected by the austenite grain size. They reheated specimens of a Fe- 0.05 pct $\mathrm{C}$ alloy to various temperatures, determined the austenite grain size at those temperatures and quantified the detrimental effect of austenite grain size on hot ductility. The stabilized austenite grain size varied from $1 \mathrm{~mm}$ at $1373 \mathrm{~K}\left(1100{ }^{\circ} \mathrm{C}\right)$ to $3.3 \mathrm{~mm}$ at $1623 \mathrm{~K}\left(1400{ }^{\circ} \mathrm{C}\right)$. Figure 7 shows that the austenite grain size following cooling the massive type of microstructure at a rate of $2100 \mathrm{~K} \quad\left(2100{ }^{\circ} \mathrm{C}\right) / \mathrm{min}$ results in austenite grains between 2-mm and 5-mm diameter. Because the specimen is only $7.6 \mathrm{~mm}$ in diameter, it is not possible to determine a statistically reliable average grain diameter, but the very large austenite grains observed when the ferrite transformation initiates, suggest that this austenite grain size is determined by the highest temperature at which austenite is stable (about $1715 \mathrm{~K}\left(1442^{\circ} \mathrm{C}\right)$ in this case). Also shown in Figure 7 is the presence of very large austenite grains. It is these large austenite grains ("blown grains" termed by Szekeres) that form at the roots of oscillation marks that are the root cause of reduced hot ductility.

It is important to assess to what extent the observations in the high-temperature microscope is relevant to continuously casting practice. For this reason, the likely surface temperature distribution in the strand in the meniscus region of the mold was calculated using industrial data, as shown in Figure 8. The temperature at the bulk surface is compared with the temperature at the root of oscillation marls of various depths.

It is evident that the cooling rate at the "hot-spot" at the roots of the oscillation marks is high enough to render a massive type of transformation morphology. It is also evident that there is sufficient time available to grow very large austenite grains at the roots of oscillation marks. Bernhard and Reiter ${ }^{[18]}$ estimated the temperature difference between the bulk surface and the root of a 0.2 -mm-deep oscillation mark to be $75 \mathrm{~K}$ $\left(75^{\circ} \mathrm{C}\right)$ at the exit of the mold. Using the same calculation technique and boundary conditions, except a different heat transfer rate, we have estimated this difference in temperature to be $150 \mathrm{~K}\left(150^{\circ} \mathrm{C}\right)$ in the 
meniscus region of the mold. Hence, significantly larger austenite grains are likely to form at the roots of oscillation marks compared with the bulk surface.

Figure 7 indicates that some austenite grains can grow at the expense of others. Although no statistically reliable information could be obtained from the small specimens, since the grain sized are comparable to the specimen diameter, abnormally large grains have consistently been observed in the evolving microstructures. It is therefore likely that abnormally large grains can form selectively at the roots of oscillation marks where the temperature is significantly higher than that of the bulk surface.

\section{CONCLUSIONS}

Our observations have shown that the delta-ferrite to austenite phase transformation in an Fe- 0.05 pct $\mathrm{C}$ alloy occurs by the propagation of planar growth fronts at low cooling rates and by a massive type of transformation mechanism at high cooling rates, in agreement with the findings of earlier research.

Very large delta-ferrite grains form very quickly on heating into the single delta-ferrite phase field and these large delta-ferrite grains transform to large austenite grains on cooling.

This large equiaxed austenite grain structure evolves from the austenite formed at high temperature irrespective of whether the phase transformation occurring by a diffusionally controlled mechanism or by a massive type of transformation.

Our observations suggest that the size of the austenite grains that eventually transform to ferrite is determined by the highest temperature of a totally austenitic structure, in agreement with the suggestions of earlier researchers.

Our experimental observations taken together with our modeling of the temperature distribution in the vicinity of the meniscus in a continuous casting mold, strongly suggest that very large austenite grains can form at the roots of oscillation marks in an operational continuous caster.

Our observations also indicate that there is a high probability that selective growth of austenite grains can occur and hence, that some grains will grow very large at the expense of others.

\section{ACKNOWLEDGMENTS}

One of the authors (Rian D) wishes to thank the University of Wollongong (Australia) for granting study leave that enabled him to collaborate with the other authors in Leoben. The authors wish to acknowledge the support of the University of Leoben (Austria) for the provision of laboratory facilities. Financial support by the Austrian Federal Government (in particular from the Bundesministerium für Verkehr, Innovation und Technologie and the Bundesministerium für Wirtschaft und Arbeit) and the Styrian Provincial Government, represented by Österreichische Forschungsförderungsgesellschaft $\mathrm{mbH}$ and by Steirische Wirtschaftsförderungsgesellschaft $\mathrm{mbH}$, within the research activities of the K2 Competence Centre on "Integrated Research in Materials, Processing and Product Engineering," operated by the Materials Center Leoben Forschung $\mathrm{GmbH}$ in the framework of the Austrian COMET Competence Centre Programme, is gratefully acknowledged.

\section{REFERENCES}

1. M. Militzer, A. Giumelli, E. B. Hawbolt and T. R. Meadowcroft: Metall Mater. Trans. A, vol. 27A, 1996, p. 3399.

2. E. S. Szekeres: Proceedings of the Sixth International Conference on Clean Steel, Balatonfüred, Hungary, 10-12 June 2002, OMBKE, Budapest.

3. V. Ludlow, A.W.A. Smith, A.S. Normanton, S. Landa, J. Wans, A. Gotti, and M. Thiemann: $4^{\text {th }}$ European Continuously Casting Conference, Birmingham, U.K., 2002.

4. J. Marcisz, B. Garbarz and A. Zak: AISTech12, 6-9 May 2012, Atlanta GA.

5. D.N. Crowther and B. Mintz: Mater. Sci. Technol., vol. 2(9), 1986, p. 671 .

6. L. Schmidt and A. Josefsson: Scand. J. Met., vol. 5, 1974, pp. 19399.

7. G. Alvarez de Toledo, A. Arteaga, and J. J. Laraudogoitia: Mater. Sci. Forum, Nov 2005, pp. 500-01.

8. H.T. Tsai, H. Yin, M. Morales and S. Morales: AISTech 05, AISTech, Charlotte, NC (2005).

9. S.-C. Moon: MEng Thesis, University of Wollongong, 2004.

10. R. Dippenaar, S.-C. Moon, and E.S. Szekeres: Iron \& Steel Technol., July 2007.

11. B. Mintz, S. Yue, and J.J. Jonas: Int. Mater. Rev., 1991, vol. 36, p. 5 .

12. E.S. Szekeres: Iron Steel Eng., vol. 73(7), 1996, pp. 29-37.

13. J. Sengupta, B.G. Thomas, H-J. Shin, and S-H. Kim: Acta Mater., 2006, vol. 54, p. 4.

14. J. Sengupta, B.G. Thomas, H-J. Shin, and S-H Kim: AISTech, Proceedings, vol. 1, 2006.

15. C.M. Chimani and K. Mörwald: ISIJ Int., 1999, vol. 39, p. 11

16. C. Chimani, G. X. Shan, K. Mörwald, O. Kolednik, H. J. Böhm, D. Duschlbauer, and T. Drabek: AISTech Proc. vol. 1, May 1-4, 2006, Cleveland OH.

17. Y. Maehara, K. Yasumoto, H. Tomono, T. Nagamichi, and Y. Ohmori: Mater. Sci. Technol., 1990, vol. 6, p. 9.

18. C. Bernhard, J. Reiter, and H. Preszlinger: Mater. Sci. Technol., MS\&T'06, Cincinnati, OH, Oct 2006.

19. B. Mintz: ISIJ Int., 1999, vol. 39, p. 9.

20. J. Miettinen, S. Louhenkilpi and L. Holappa: ISIJ Int., 36, 1996.

21. C. Bernhard, J. Reiter, and H. Presslinger: Metall. Mater. Trans. B, 2008, vol. 39B, pp. 885-95.

22. S. Niknafs: MEng Thesis, University of Wollongong, 2007.

23. S. Niknafs and R.J. Dippenaar: Direct Observation of High-Temperature Phase Transformations in Steel: Delta-Ferrite to Austenite Phase Transformation, Dr Saarbrücken, Müller, 2009.

24. Z. Liu, Y. Kobayashi, J. Yang, K. Nagai, and M. Kuwabara: ISIJInt., 2006, vol. 46, p. 6.

25. H. Shibata, Y. Arai, M. Suzuki, and T. Emi: Metall. Mater. Trans. $B$, vol. 31B, 2000, p. 981

26. N. Kikuchi, S. Nabeshima, Y. Kishimoto, J. Nakano, and S. Seetharaman: ISIJInt., 2008, vol. 48, p. 7.

27. C. Bernhard and T. Sjökvist: Berg- und Huettenm. Mon., vol. 151, 2006, p. 5. 